\title{
Reservoir Characterization of the B-Interval of Lower Goru Formation, Miano 9 and 10, Miano area, Lower Indus Basin, Pakistan
}

\author{
Mehmood Raza ${ }^{1}$, Fawad Khan ${ }^{1}$, Muhammad Yasin Khan², Muhammad Tayyib Riaz ${ }^{2}$, Umair Khan ${ }^{3}$ \\ ${ }^{1}$ Center of excellence in Mineralogy, University of Baluchistan, Quetta 87300, Pakistan \\ ${ }^{2}$ Institute of Geology, University of Azad Jammu and Kashmir, Muzaffarabad 13100, Pakistan \\ ${ }^{3}$ School of Geosciences and Info-Physics, Central South University, Changsha 410083, China
}

Corresponding Author Email: Yasin.khan@ajku.edu.pk

https://doi.org/10.18280/eesrj.070103

Received: 15 December 2019

Accepted: 24 January 2020

\section{Keywords:}

success, seismic, wells, elastic, corresponding

\begin{abstract}
In order to get a higher success rate and a small number of wells for development, the reservoir characterization was carried out using seismic, Petrophysical and rock physics data in the B-interval of Miano 9 and 10, Miano area, Lower Indus Basin, Pakistan. For this purpose, at first, the wells and shot points of seismic lines were located on a base map. Then, the horizons were marked on seismic sections and further interpreted on the Time Depth (TD) charts. Moreover, a synthetic seismogram relaying the seismic and well data was made. In addition, different Petrophysical parameters were calculated using well $\operatorname{logs}$ and the geological properties of rocks were related with the corresponding elastic and seismic properties in analyzing the rock physics. The study indicates that the area is deformed by horst and graben structure in subsurface and lateral extents of faults were marked by fault polygons. The higher hydrocarbon saturation, porosity and permiability as determined through well logs and the low elastic properties calculated through rock physics in B-interval of Miano 9 and 10 indicate a good potential zone of Hydrocarbon. The finding of this research work is useful to understand the subsurface geology and hydrocarbon potential of the area.
\end{abstract}

\section{INTRODUCTION}

Sound waves bounces back after striking the rock formations. When they return back they are being detected through different sensors. Wave's time and frequency provides valuable information about the formation, rock types and possible oil and gas reserves [1]. Seismic method gives accurate information in drilling a well [2]. It can explore the subsurface earth more precisely and gives the detailed information about earth model, and thickness of earth's layers along with weathered layer [3, 4]. The whole purpose of this research work is to interpret the subsurface structures on the basis of reflection data.

Seismic structural interpretation is the method which tells more about the subsurface structures i.e. orientation of fault, depositional settings and information about horizons [1-4]. This method configures the arrival time/depth of subsurface structures by creating different maps i.e. time and depth mainly. Main elements for interpretation are the identification/mapping of Formation boundaries and faults present on the seismic section [5]. Usually Faults, folds, anticlinal structures, duplex and pop-ups are included in structural traps [6].

Continuous recording of physical properties of rocks with depth is called well logging. The main objectives are to identify pay zone of hydrocarbons, Petrophysical parameters i.e., porosity, permeability, saturation of hydrocarbon, lithology, physical and chemical rock properties. Rock physics provides a link between geological reservoir parameters e.g. Porosity, clay content, sorting, lithology, saturation and seismic properties e.g. acoustic impedance, Pwave/S-wave, velocity ratio Vp/Vs, bulk density, Poisson's ratio and elastic module [7]. Different logs i.e., neutron, SP and gamma ray log are being used to identify depositional settings. This information helps us to identify stratigraphic sequences [8].

The main objective of this work was to get a higher success rate and only a few wells for exploitation in the area. The objectives of research work are as follows:

a. Detailed seismic interpretation for identification of structures favorable for hydrocarbon accumulation as discussed in the sections, 4.1.1 to 4.1.10.

b. Petrophysical analysis for identification of hydrocarbon bearing zone as discussed in the sections, 4.1.11 to 4.1.20.

c. Rock physics evaluation for reservoir zone as discussed in the sections 4.1.21 to 4.1.27.

\section{STUDY AREA}

Miano (Block-20) zone falls within 62 kilometers southeast of Sukkur city Sindh, Pakistan Figure 1. It is lingering almost $42 \mathrm{~km}$ adjacent to the strike. Mari and Sui gas fields, the two productive fields of Pakistan are situated individually $75 \mathrm{~km}$ and $150 \mathrm{~km}$ towards north of the Miano field. The eight wells have been penetrated till today in the B-Interval of Lower Cretaceous Guru Formation [9]. Geologically, it is constrained between the Indian basement and the Kirthar Fold and Thrust belt. The cardinal points of 
upper left $\left(27^{\circ} 36^{\prime} 35.9^{\prime \prime} \quad \& \quad 6^{\circ} 12^{\prime} 57.1^{\prime \prime}\right)$, upper right (273' $\left.35.9^{\prime \prime} \& 6^{\circ} 27^{\prime} 30.4^{\prime \prime}\right)$, lower left $\left(27^{\circ} 14^{\prime} 18.4^{\prime \prime} \&\right.$ $\left.69^{\circ} 12^{\prime} 43.1^{\prime \prime}\right)$ and lower right $\left(27^{\circ} 14^{\prime} 10.1^{\prime \prime} \& 69^{\circ} 27^{\prime} 51.8^{\prime \prime}\right)$ falls on the map. Geological margins and positions of Miano extent are presented in Figure 1.

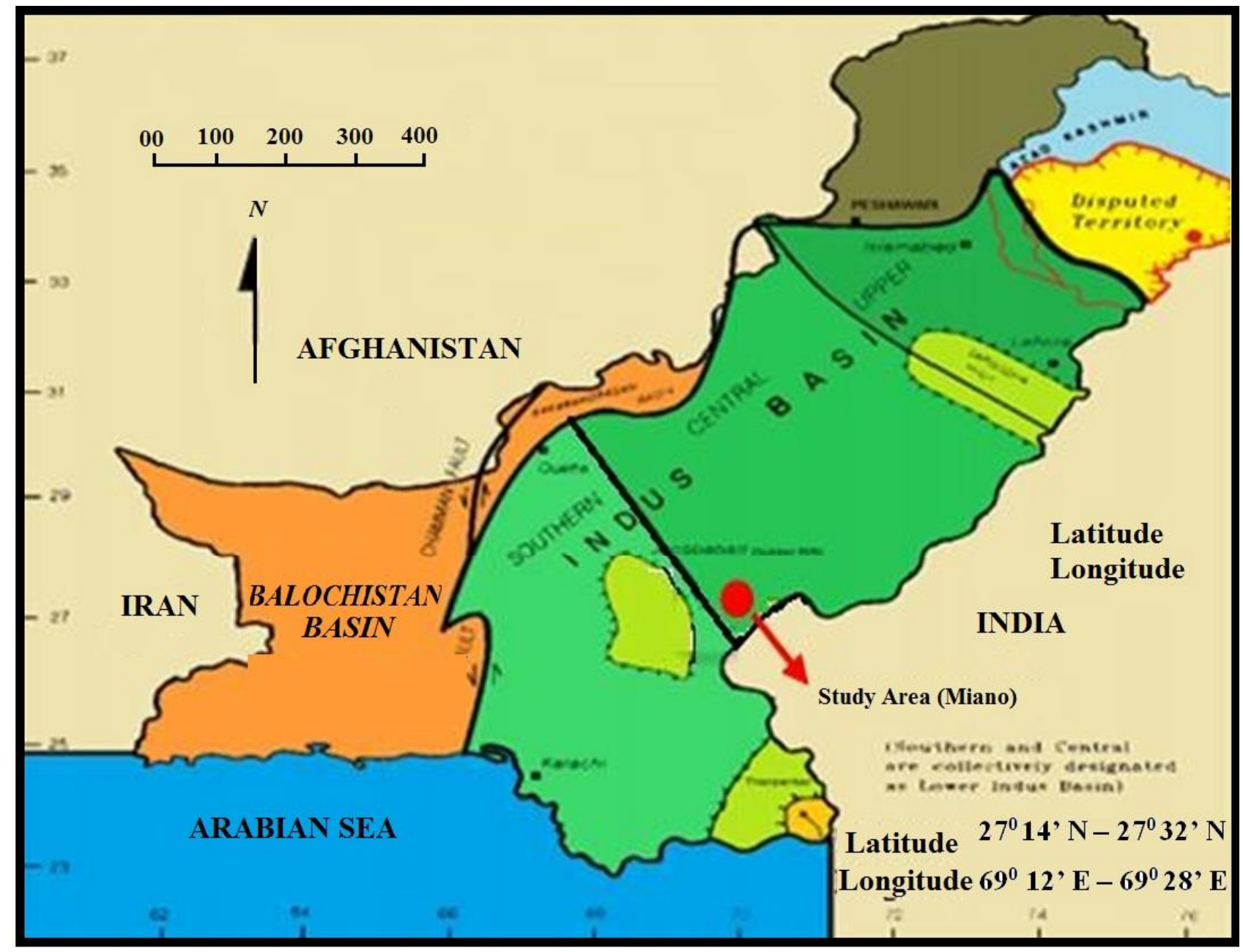

Figure 1. Study area on the map [10]

The area under consideration (Miano) in the Sindh Province of Pakistan is a joint venture amongst OMV Exploration (Pakistan), ENI Exploration and Production Limited (Italy), Pakistan Petroleum Limited (PPL) and Oil and Gas Development Company Limited (OGDCL). The production to date has been obtained through seven wells out of eighteen penetrated in the region. Miano raw gas is being handled at upgraded Kadanwari gas processing plant. At present, Kadanwari plant is handling on an average 185 Million standard cubic feet per day (MMSCFD). The Miano8 well was tied in to production services in June, 2005. Average gas trade of Miano field is round about 145 MMSCFD. The average daily trade throughout 2004-05 (up to May 2005) from the field was 141.22 MMSCFD for refined gas, and 104 barrels for condensate (Pakistan petroleum Limited).

\section{STRATIGRAHIC SETTINGS}

Miano area comprises mainly of sedimentary rocks, Permian to Mesozoic aged, overlain by an angular unconformity of late Paleozoic age. At surface, there is no out crops present as the whole area is overlain by an alluvium sheet which results a successive stratigraphic column as shown in the Figure 2. An inclined gentle slope with eastward direction has deposited a Progradational sequence of Mesozoic. Permian, Triassic and early Jurassic sedimentary rocks consist of inter-bedded sandstone, siltstone and shale of continental to shallow marine origin. The area is mainly comprised of continental to shallow marine sedimentary rocks i.e., sandstone, siltstone and shale of Permian, Triassic and early Jurassic age [11].

Chiltan Limestone of early to middle Jurassic shows very prominent reflector in seismic section with very smooth character. Limestone of Chiltan Formation is bounded by Late Jurassic to Early Cretaceous regressive strata of topsets, bottom sets and foresets, from top and bottom.

Sember Formation comprises mainly of black shale with subordinate siltstone, sandstone and hydrocarbon source in Middle and Lower Indus basins with 0.5 to 3.5 percent of TOC's range. As Sember Formation has been deposited in marine environment so it contains type III Kerogens of organic matter whereas, type II Kerogens are also present [12]. The regressive stratum topsets progrades Lower Goru Formation which comprises "A", "B", "C", and " $\mathrm{D}$ " members. These members have deposited during changes in sea level from high to low rapidly. That also refers to a prograding sequence with slightly aggradational sequence [13]. 


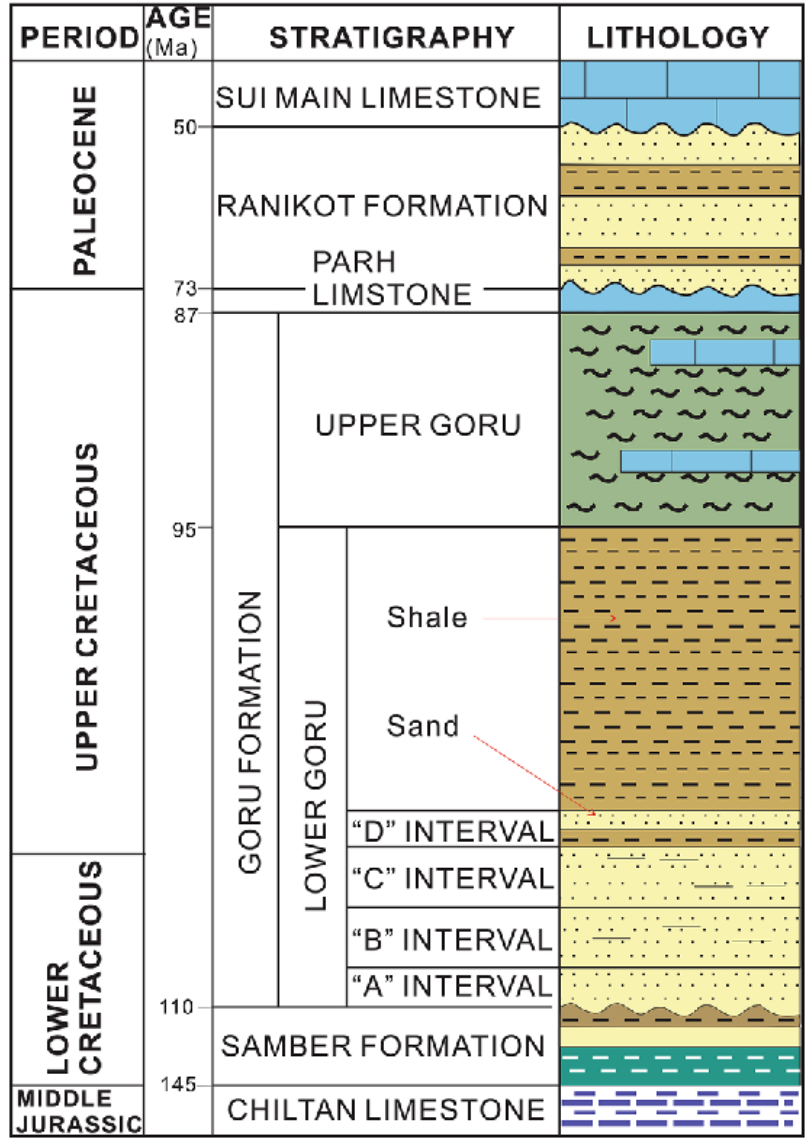

Figure 2. Stratigraphy of area after $[13,14]$

\section{MATERIAL AND METHOD}

Seismic Techniques are the genuine procedures used at the present time to detect hydrocarbon reserves, geothermal pools and groundwater. It delivers borehole, geophysical and geological records by making use of elastic waves as done in this research. It delivers information regarding the structure and distribution of rock forms in the subsurface [15]. In seismic reflection studies seismic energy poundings are noted down which are returned back from the subsurface margins. The traveling time and profundity of reflecting planes can be deliberated from the information acquired through the reflecting interfaces.

\subsection{Work flow for seismic interpretation}

The workflow charted for interpretation is prearranged in Figure 3. Initially, a base map was organized by loading navigation and Seg-Y records in IHS kingdom software. Then faults were mapped out on the foundation of geology. In addition, the seismic horizons were discerned using Time Depth (TD) chart and then confirmed by making a synthetic seismogram. Moreover, the Faults polygons were produced to perceive the structural extents, existing in the studied area. Meanwhile, the time and depth contour maps revealing the subsurface structure in the research area were also compiled.

As the seismic interpretations were carried out step by step. The details of different steps performed in seismic interpretation are described in detail under the sections 4.1.1 to 4.1.10. Moreover, the results obtained through these stages were further elaborated in the figures and tables in individual section.

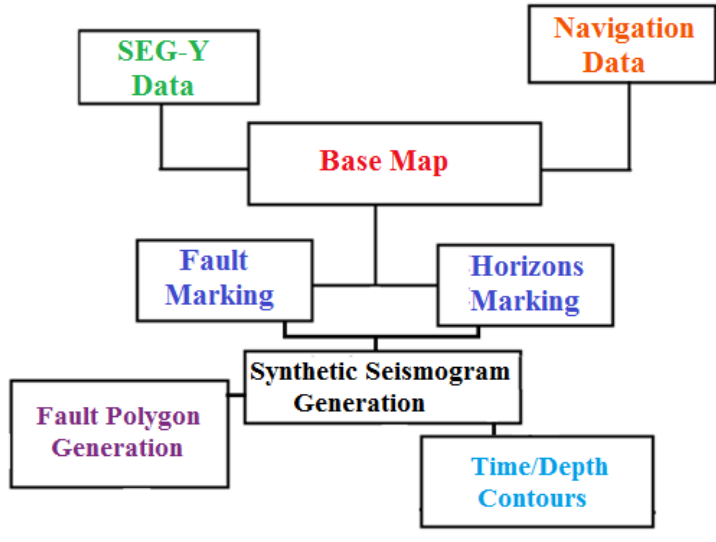

Figure 3. Work flow of seismic interpretations

\subsubsection{Seismic data}

The data employed for recent exploration was comprised of 11 seismic lines and three wells Miano-7, Miano-9 and Miano-10. Four lines and two wells (in bold) were dispensed to us for the accomplishment of this exploration work. The details of seismic lines are revealed in Table 1.

Table 1. Seismic Lines data of research work

\begin{tabular}{|c|c|c|c|}
\hline Line Number Direction & Shot Points & Line Type \\
\hline P2094-211 & N-S & $102-739$ & Dip \\
\hline P2094-212 & E-W & $102-739$ & Strike \\
\hline P2094-213 & N-S & $102-740$ & Dip \\
\hline P2094-214 & E-W & $102-1175$ & Strike \\
\hline P2094-215 & N-S & $102-1175$ & Dip \\
\hline P2094-216 & E-W & $102-1136$ & Strike \\
\hline P2094-217 & N-S & $102-916$ & Dip \\
\hline P2094-219 & N-S & $102-1140$ & Dip \\
\hline P2094-220 & E-W & $102-785$ & Strike \\
\hline P2094-221 & N-S & $102-1142$ & Dip \\
\hline P2094-223 & N-S & $102-1153$ & Dip \\
\hline
\end{tabular}

\subsubsection{Well data}

Miano-09 and Miano-10 gas wells of the block-20 were penetrated up to profundity of $3310 \mathrm{~m}$ to $3160 \mathrm{~m}$ in the Lower Goru "B', and "C" Sand Intervals. The comprehensive statistics of the wells is set in Table 1 .

\subsubsection{Technical well data information}

Formations tops and elementary well data facts have been uploaded in order to display them on Base Map. The basic information of Miano-09 and Maino-10 has been displayed in the Table 2 .

Table 2. Details of well data of Miano-9 and Miano-10

\begin{tabular}{|c|c|c|c|}
\hline Wells & Longitude & Latitude & Elevation \\
\hline Miano-09 & $069^{\circ} 31^{\prime} 14.78^{\prime \prime}$ & $027^{\circ} 37^{\prime} 17.47^{\prime \prime}$ & $3385 \mathrm{~m}$ \\
\hline Miano-10 & $069^{\circ} 31^{\prime} 33.83^{\prime \prime}$ & $027^{\circ} 39^{\prime} 25.28^{\prime \prime}$ & $3610 \mathrm{~m}$ \\
\hline
\end{tabular}

\subsubsection{Base map}

The Base map holds the information regarding the well sites, concession frontlines along with the alignments of seismic survey outlines and seismic surveys shot points. Furthermore, it contains cultural data i.e., roads, erections with geographic data information or Universal Transverse Mercator (UTM) grid information. The base map of the area under consideration is presented in the Figure 4. The Base 
map displays four South West oriented strike lines and seven North South oriented dip lines with two wells of Miano block-20.

\subsubsection{Seismic horizons}

The four seismic lines (P2094-214, P2094-216, P2094-219
\& P2094-223) were selected for interpretation. Of these horizons were discerned on the strike lines P2094-214 and P2094-216. In this work horizons were outlined on the seismic line P2094-223 before tying with further lines. Moreover, a synthetic seismogram was organized to confirm the marked horizons.

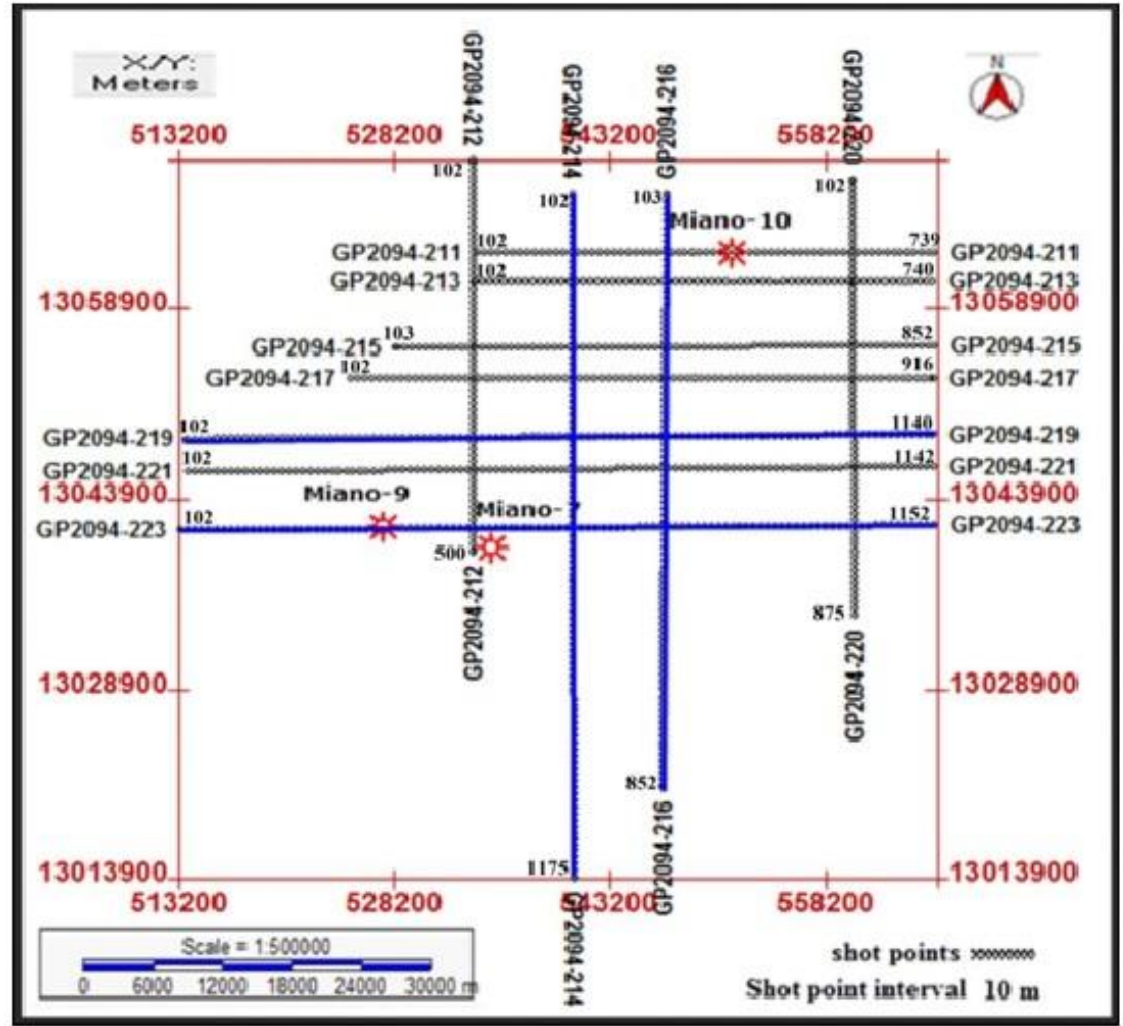

Figure 4. Base map of the Miano block-20

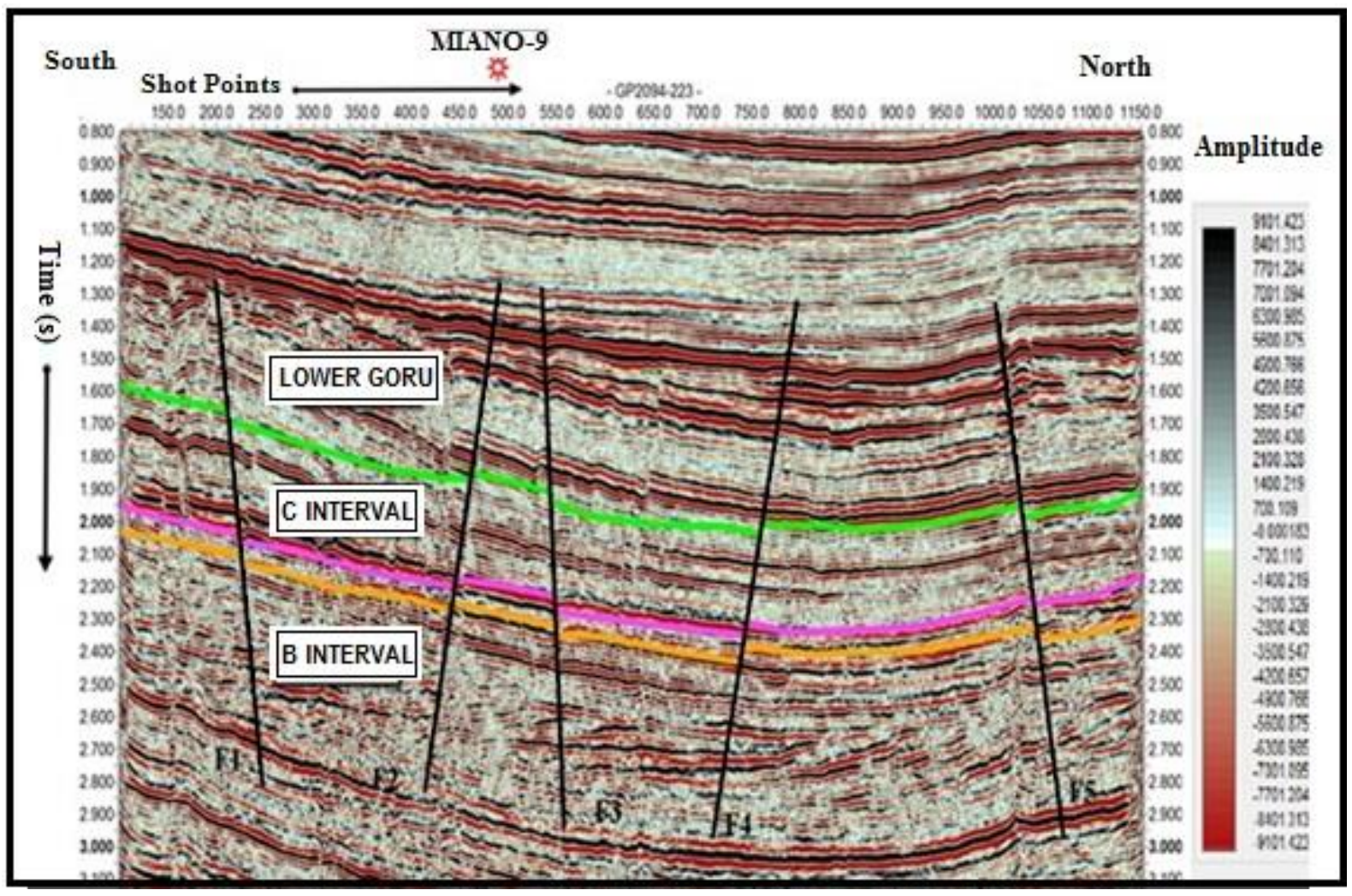

(a) Faults in interpreted dip line P2094-223 


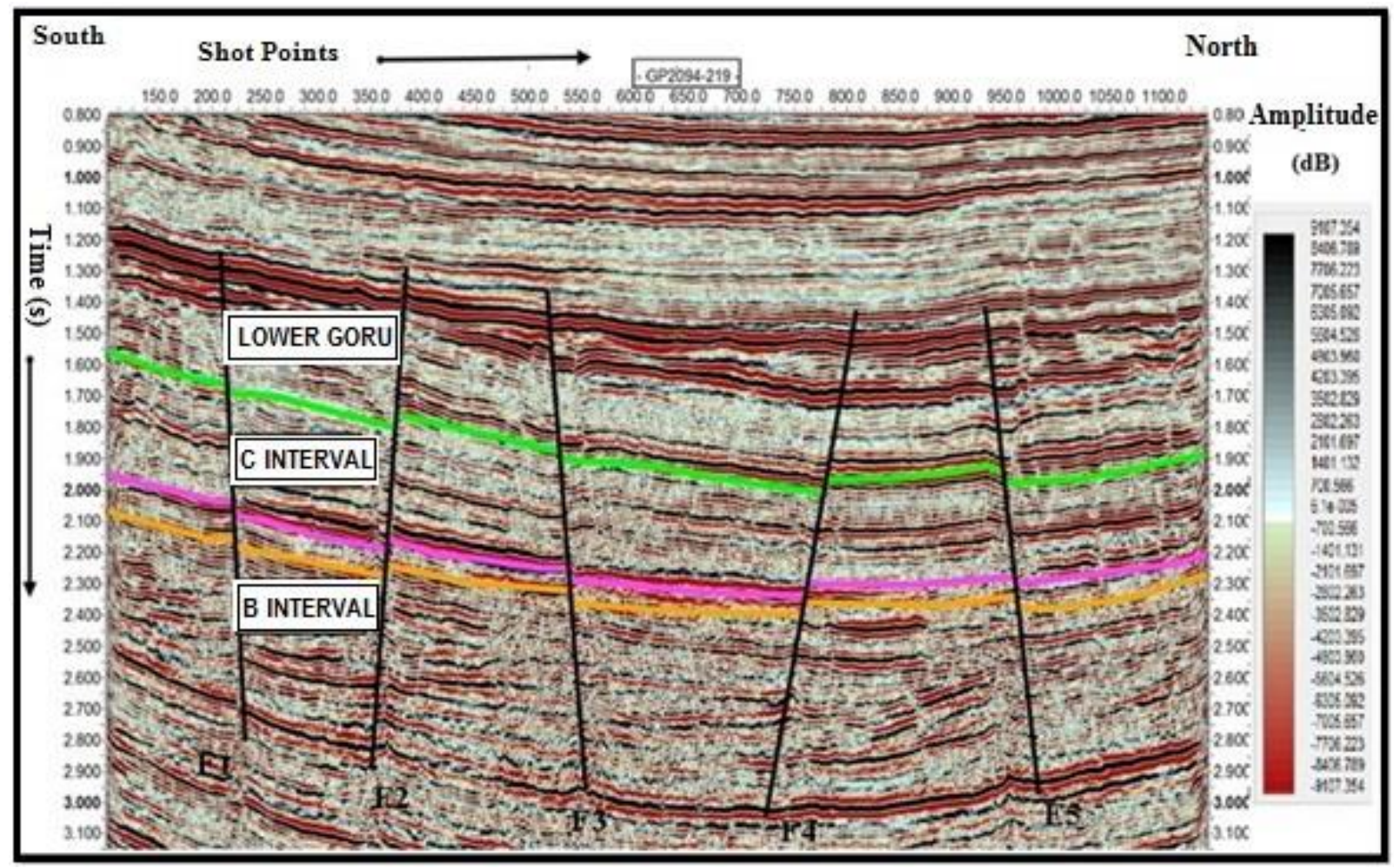

(b) Interpreted strike line P2094-216

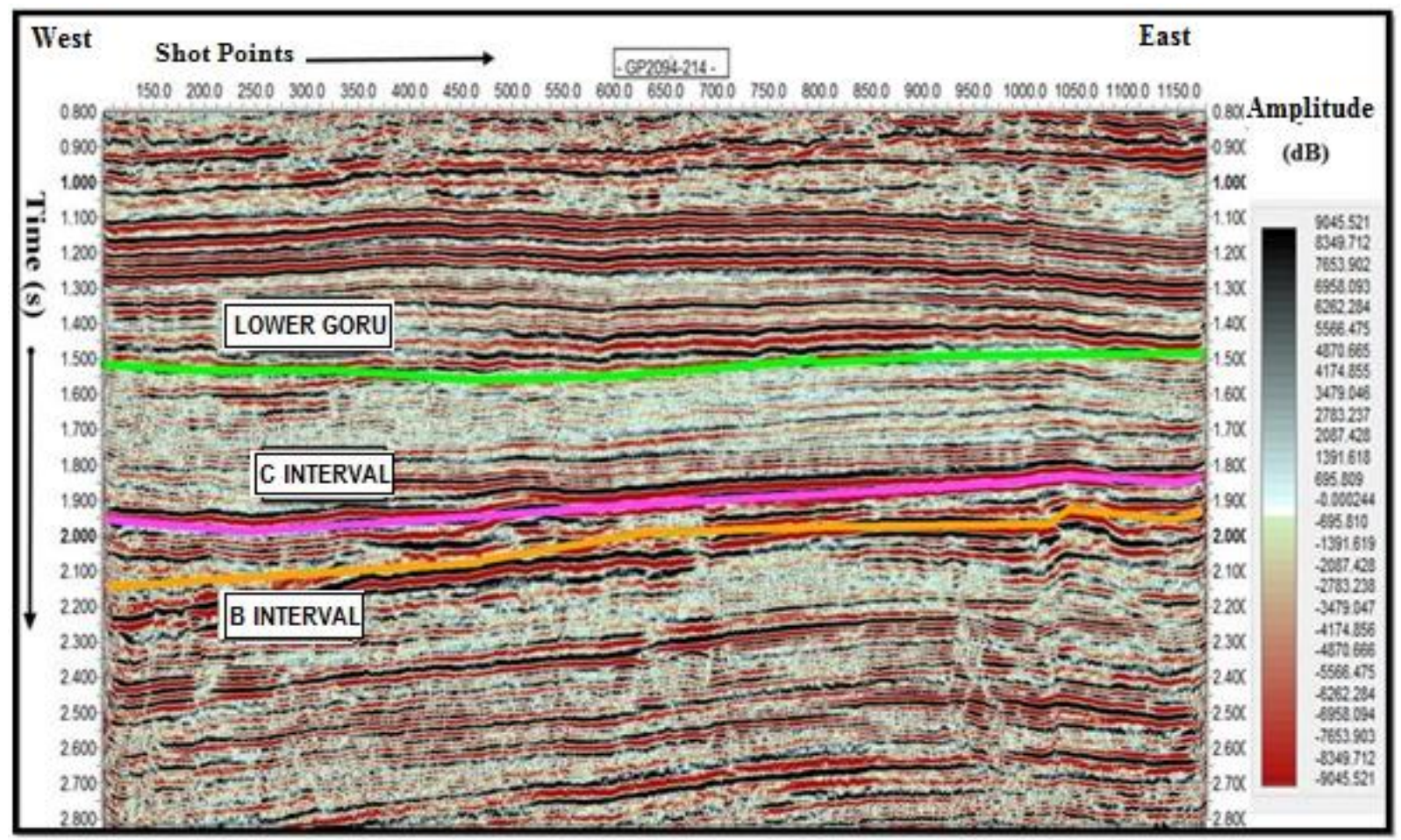

(c) Interpreted strike line P2094-214

Figure 5. B-interval on different seismic hozons

As the seismic data includes time and well data includes profundity, so horizons were not in a time format. The synthetic seismogram, however, settled two-way travel time contrary to each formation's depth reserved from time depth chart for earlier marked horizons. The synthetic seismogram was employed in the establishment of Interval-B horizon on a corresponding line. Interpreted dip and strike lines on seismic horizons are individually presented in Figure 5 (a), (b) and (c). The three horizons were marked and their time is documented in Table 3.
Table 3. Time of marked horizons along with color display

\begin{tabular}{|ccc|}
\hline Horizons & Time(s) & display colors \\
\hline Lower Goru & 1.61 & Green \\
\hline C Interval & 2.08 & Pink \\
\hline B Interval & 2.17 & Gold \\
\hline
\end{tabular}




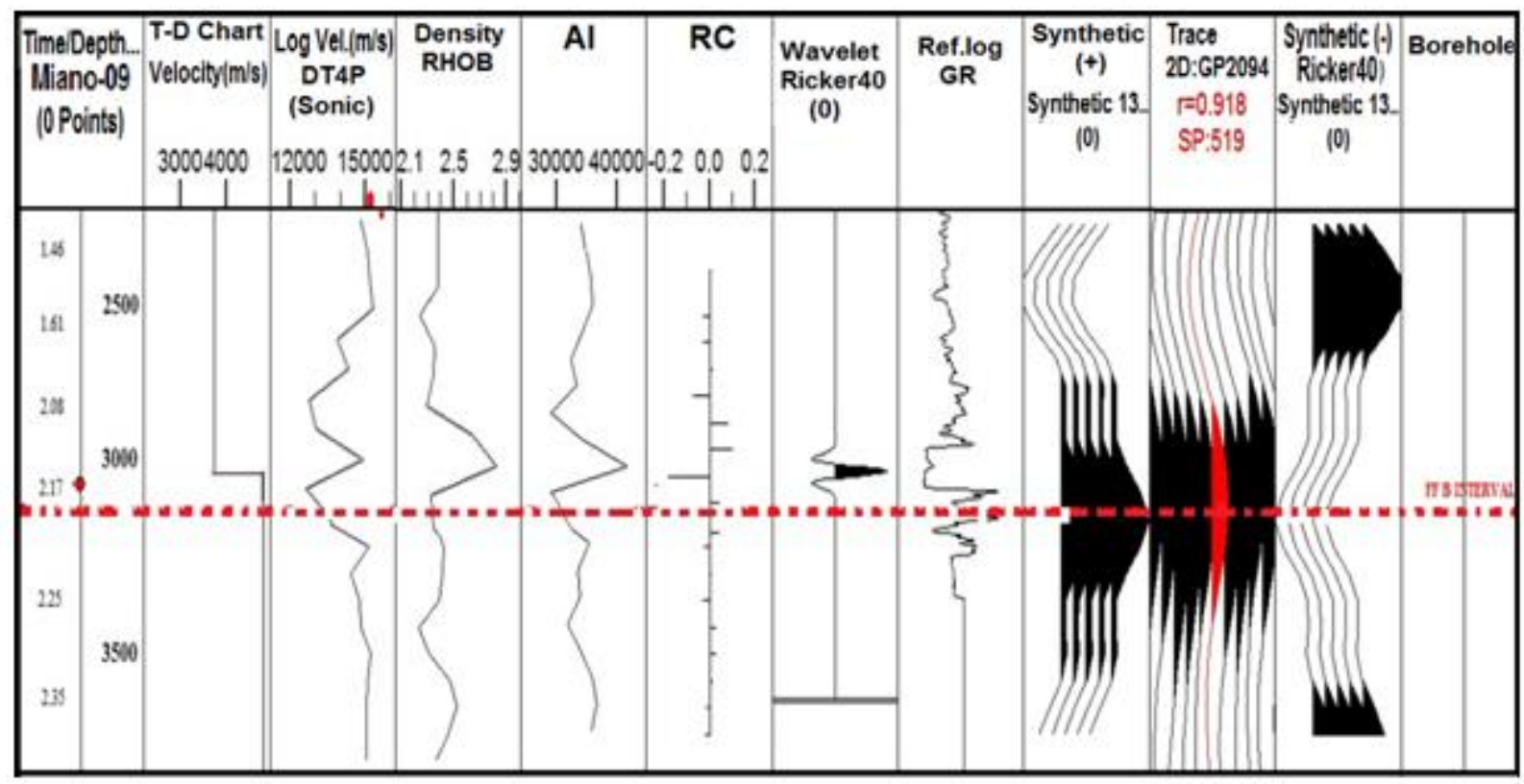

Figure 6. Synthetic seismogram of Miano-9

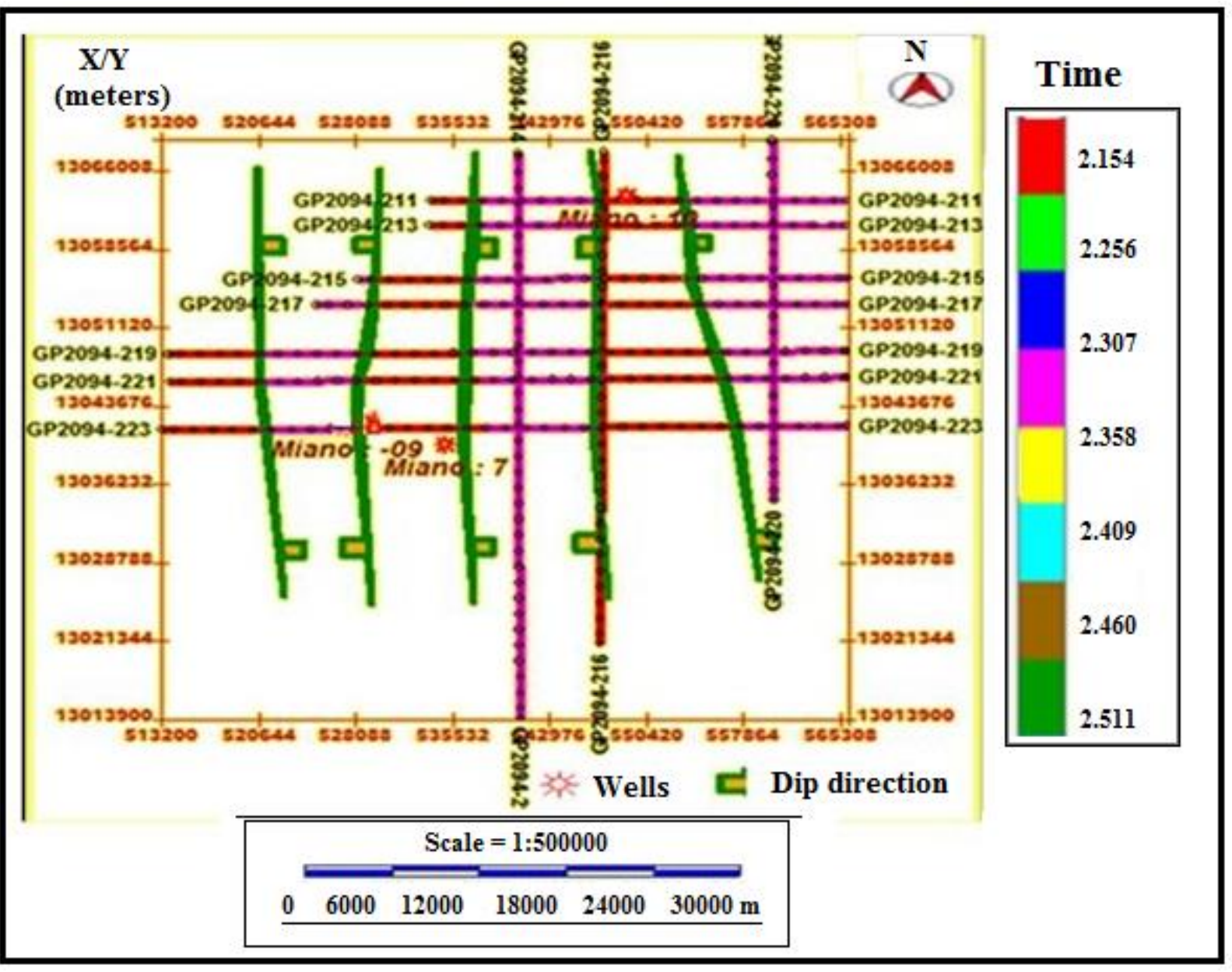

Figure 7. Fault polygon of B-interval

\subsubsection{Generation of synthetic seismogram}

Two way time (TWT) for discrete well top was required in making a synthetic seismogram. The TWT was analysed using sonic log from the well bore. Moreover, the digital data of sonic and density logs were multiplied in creating an impedance log [16] (Eq. (1)). The acoustic impedance (AI) log was used to consider a Reflection Coefficient (RC) series by establishing a relation as assumed in Eq. (2) and a synthetic seismic trace was made by formulating a source wavelet (Ricker Wavelet) and convoluting it with a reflection coefficient sequence as revealed by Eq. (3).

Convolution of wavelets with RC series means the amalgamation of both, source wavelet and reflection coefficient. mathematically can be documented as following: 
Acoustic impedence (I)

$=V p($ Sonic $\log ) *$ Density $($ Rhob $)=\rho v$

Reflection Coefficient $=(\rho 2 V 2-\rho 1 V 1) /(\rho 2 V 2+$

$$
\rho 1 V 1)
$$

Seismic Reflection $=$ Seismic source wavelet $*$ Earth reflectivity

Synthetic Seismogram $=$ Source wavelet $*$ RC-Series

The Synthetic seismogram of Miano-9 well, formulated through the Eq. (4) and shown in Figure 6, fell on the seismic line P2094-223 and it agreed with the horizonal marking.

\subsubsection{Generation of fault polygons}

The Fault Segment refers to the fault on seismic sections while Fault Polygon is the term used for the fault on a map. On entire seismic lines, the lateral extents of the faults were displayed by the fault polygons. The Fault polygons were geared up only for Interval-B (Figure 7).

\subsubsection{Contour maps}

The structures developed in a certain horizons are found usually through contouring in seismic interpretations. Formation and reference datum were nominated in subsurface contouring.

\subsubsection{Time contour maps}

At the level of horizons, the lateral and vertical discrepancies with respect to time are shown by the time contour maps as it marks the outline of subsurface structures. Time contour map is made for B-interval Figure 8. In short, the 2-D variations in Time lapses are depicted in Time contour maps.

\subsubsection{Depth contour maps}

It represents discrepancies with respect to profundity. For depth contour map velocity through seismic line P2094-221 was analyzed on the Matlab programme.

Hence, Matlab program was used and CDP gathers of seismic line P2094-221 was employed and a plot was attained, revealing a very small disparity in the average velocity for Lower Goru horizon B-interval. The iso-velocity of almost $2300 \mathrm{~m} / \mathrm{s}$ was used to transfer time into depth contour map. The analyzed velocity plot is presented under neath in Figure 9 (a) with remarkable B-interval.

After velocity analysis and finding a distinct velocity, depth contour map is compiled for Interval-B horizon (Figure 9 b) by using following formula:

$$
d=v^{*} t / 2
$$

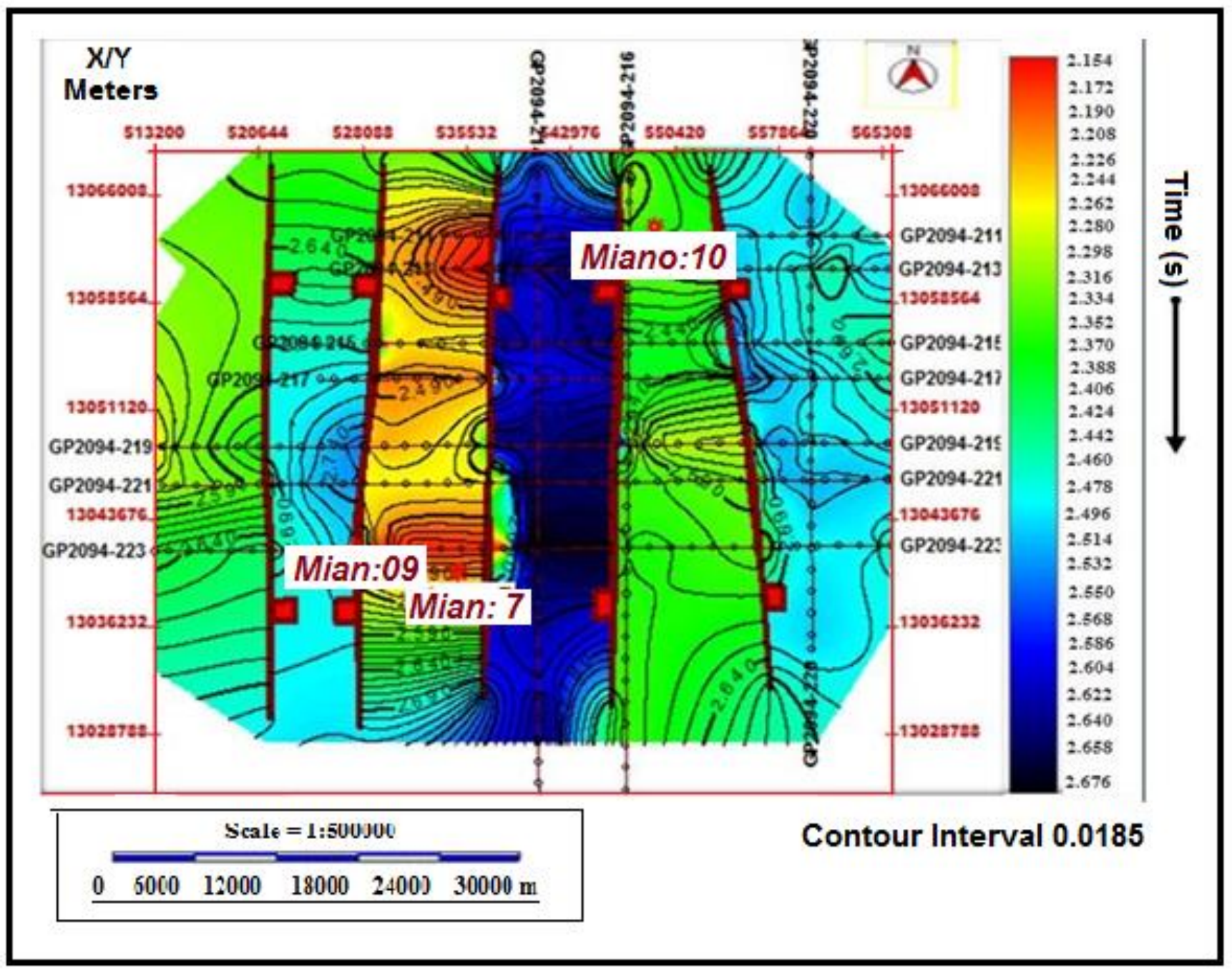

Figure 8. Time contour map of B-interval 


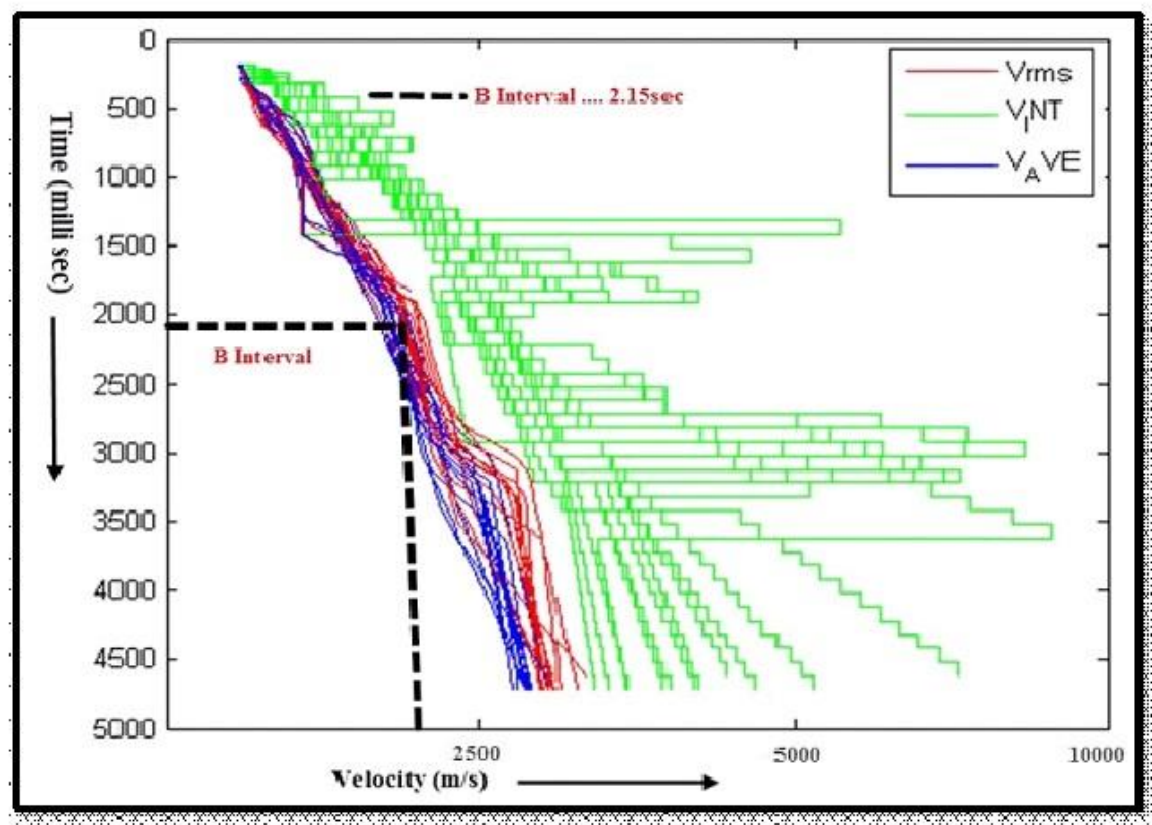

(a) Velocity analysis of Line P2094-221

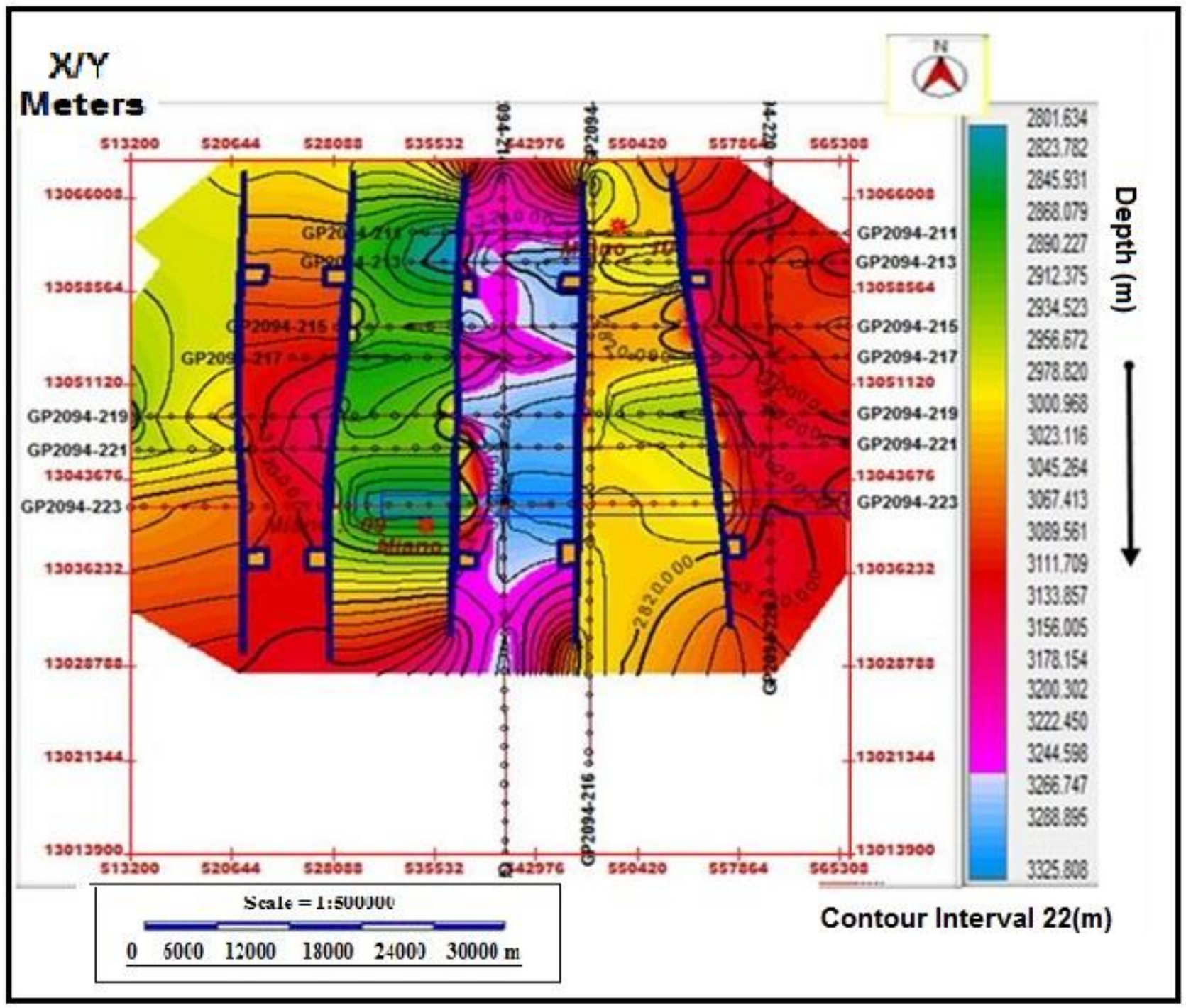

(b) Depth contour map of B-interval

Figure 9. Velocity analysis and depth contour map 


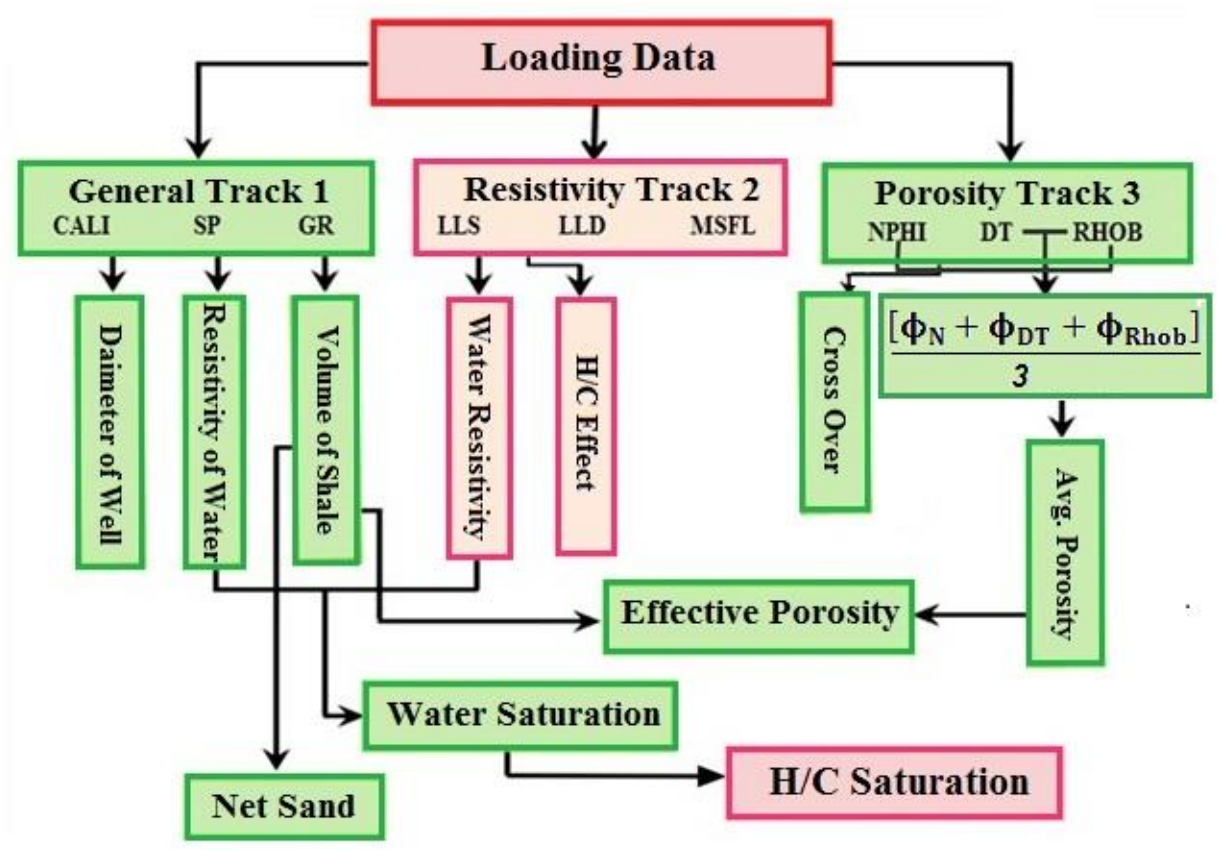

Figure 10. Petrophysical analysis wok flow

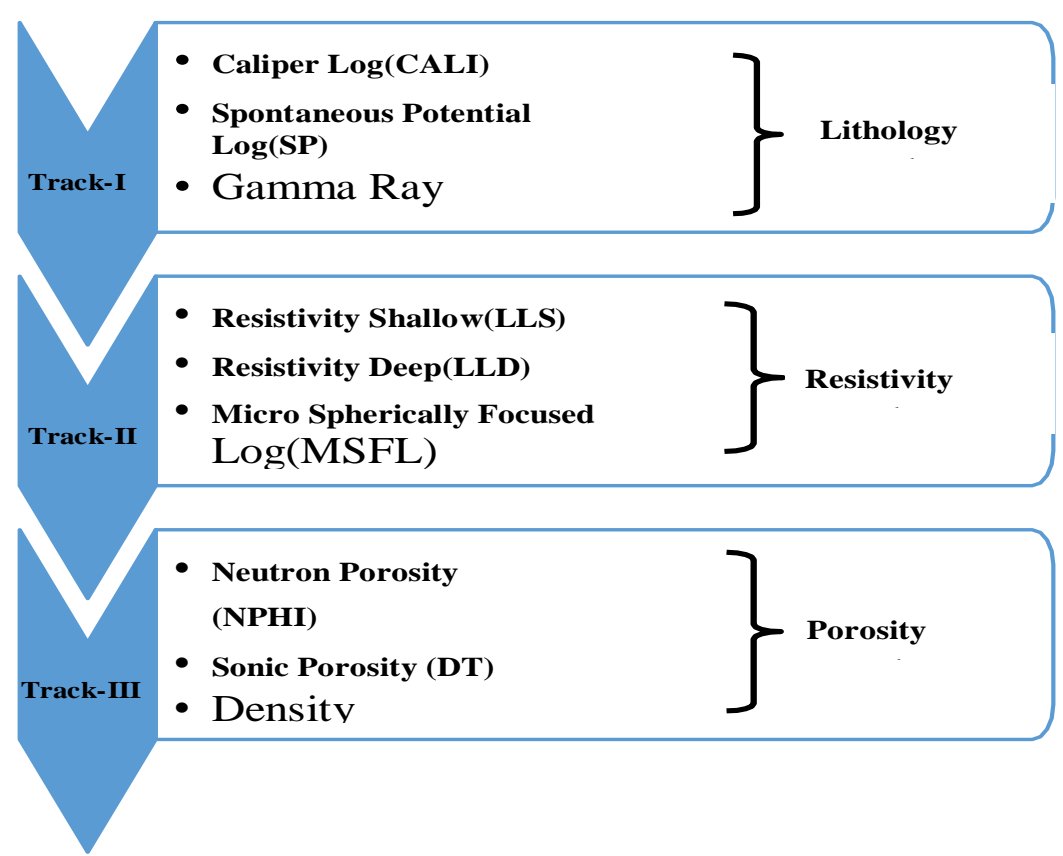

Figure 11. Basic three log tracks

\subsubsection{Well logging}

The log data of Miano-9 and Miano-10 was available in Logging ASCII Standard (LAS) format. The methodology adopted for this work is given in Figure 10. For calculating rock properties IHS kingdom software was used in which first we have loaded the well data then defined different tracks.

The defined logs are displayed in tracks by conveying ranges to each log and then different parameters of rocks for both wells Minao-9 and Minao-10 are calculated. Moreover, the hydrocarbon zones were marked and required results were obtained and discussed in later sections.

The subsequent rock properties were calculated using well logs:

By means of gamma-ray log presence of reservoir rock was identified.
Net sand and net pay was calculated.

Volume of shale was found.

Porosity was determined.

Water Saturation was obtained.

The hydrocarbon bearing zone was detected.

\subsubsection{Raw log curve}

Well data of Miano-9 andMiano-10 was used for prospect analysis. This procedure was carried out in HIS kingdom 8.6. For Petrophysical analysis the logs and different Tracks are shown in Figure 11.

\subsubsection{Calculation of rock properties of Miano-9 and 10}

Petrophysical properties of B-interval were calculated in Miano-9 and Miano-10. Depth interval of both wells are shown in the Figures 12 ( $\mathrm{a} \& \mathrm{~b})$. 


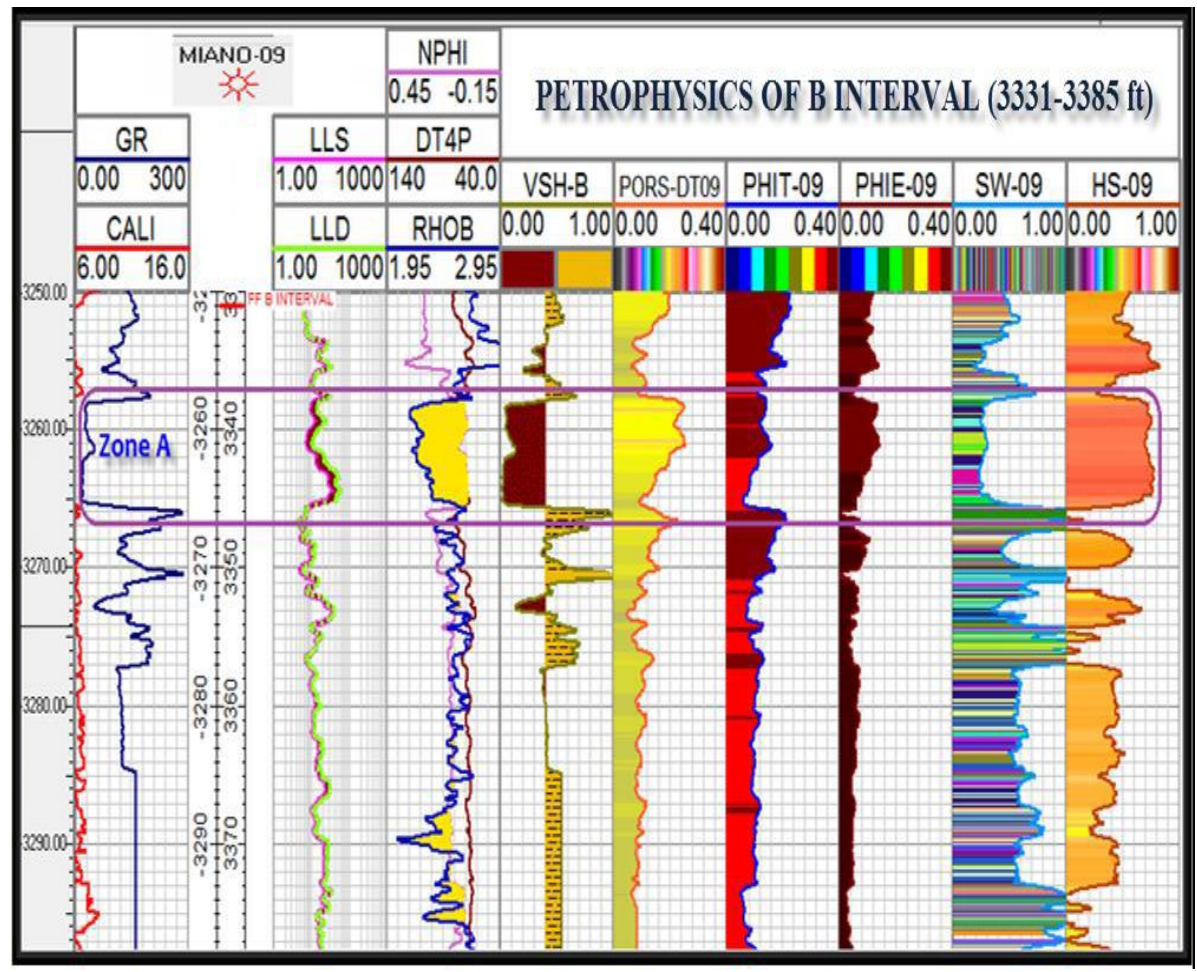

(a) Miano-9 well

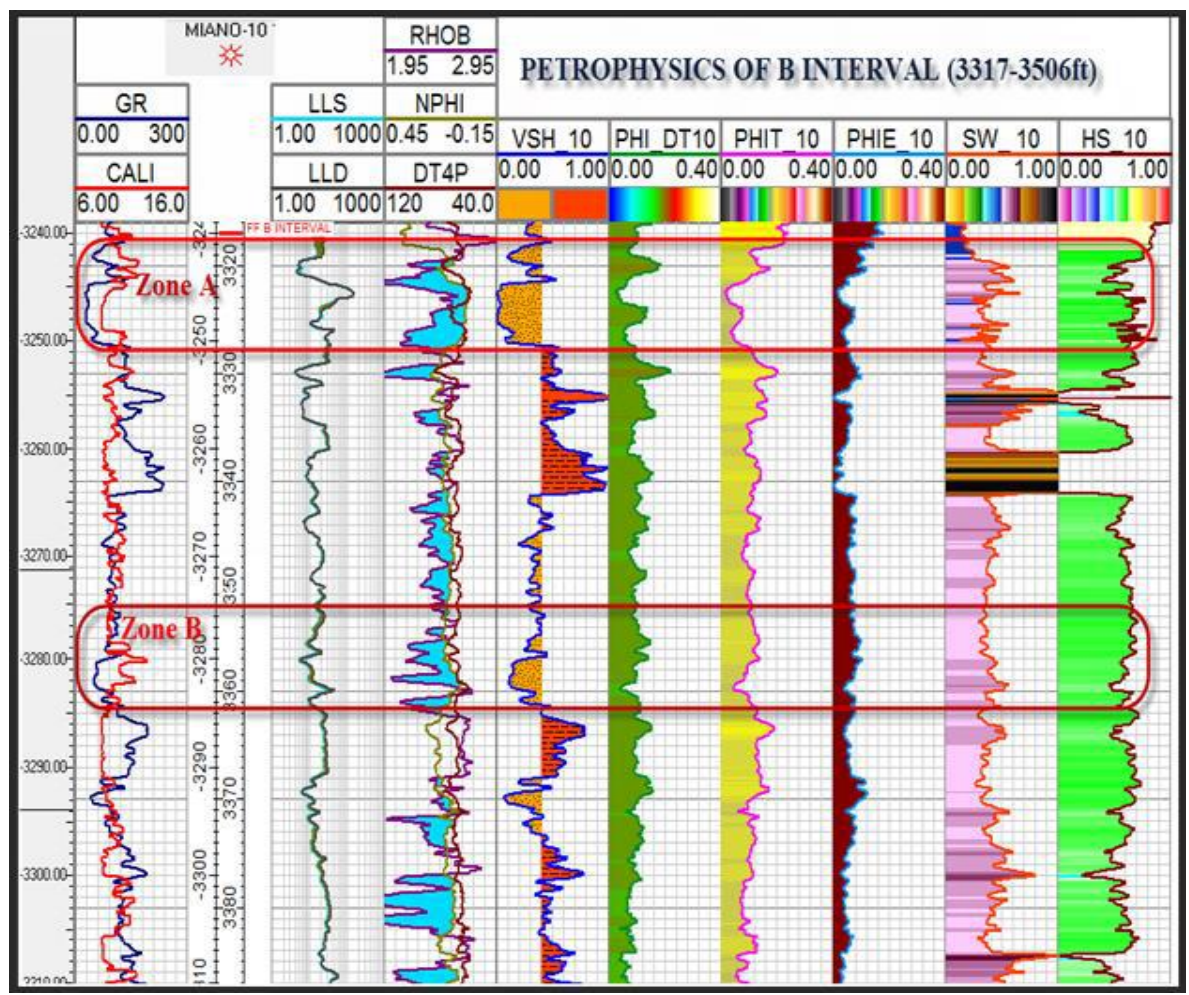

(b) Miano-10 well

Figure 12. Petrophysical analysics of Miano-9 and Miano-10

\subsubsection{Volume of shale}

Shale content reads higher GR value as compared to the sandstone or limestone. Volume of shale is to be subtracted through formation in order to get volume of true formation.

$$
V_{S h}=\left(G R_{L o g}-G R_{\min }\right) /\left(G R_{\max }-G R_{\min }\right)
$$

\subsubsection{Sonic porosity}

It measures the travel transit time $(\Delta t)$ of shear and compressional sound waves along borehole axis. Formula and calculation of sonic porosity is given below:

$$
\Phi S=(\Delta T-\Delta T m a t) /\left(\Delta T_{f}-\Delta T_{m a t}\right)
$$

According to Wyllie interval transit time $(\Delta \mathrm{T})$ increased due to the presence of hydrocarbon (i.e. hydrocarbon effect). In order to correct this [17] suggested the following empirical corrections using equation (7) and (8) for hydrocarbon effect.

$$
\begin{gathered}
\Phi=\Phi_{S} \times 0.7(\text { for gas }) \\
\Phi=\Phi s \times 0.9(\text { for oil })
\end{gathered}
$$




\subsubsection{Neutron porosity}

Neutron logs measures the porosity of rock formation with the help of hydrogen content present there. Its symbol is $\Phi \mathrm{N}$.

\subsubsection{Total porosity}

Sonic porosity and neutron porosity are used for calculating total porosity.

$$
\Phi T=\varphi s / 2 \varphi n
$$

\subsubsection{Effective porosity}

It is defined as "the ratio of the volume of interconnected pore in a rock unit to the total volume of the rock by removing the shale effect in that rock unit". The following relation is used for the determination of effective porosity [18].

$$
\boldsymbol{\Phi}_{e}=\boldsymbol{\Phi}_{S}+\boldsymbol{\Phi}_{n} / 2 *(1-V s h)
$$

\subsubsection{Water saturation $(\mathrm{Sw})$}

It reads the percentage of effective porous water filled rock volume. It is calculated by using the following formula given in Eq. (12) known as Archie equation.

$$
S w=\sqrt{ } F \times R w / R t
$$

Since, $F$ is the formation factor written as

$$
F=a / \emptyset^{n}
$$

So, it is evident from Eq. (12) that to evaluate saturation of water we have to find its resistivity $(R w)$.

\subsubsection{Hydrocarbon saturation $\left(S_{h c}\right)$}

It is defined as the hydrocarbon present in the fraction of pore spaces. Hydrocarbon saturation can be calculated by using the Eq. (14).

$$
S_{h c}=1-S
$$

The summation of results obtained by using Eqns. (6) to (14) for the Zone A of B-interval in Miano-9 and B-interval of Miano-10 are summarized in the Tables 4 and 5

\begin{tabular}{|c|c|c|c|}
\hline $\begin{array}{l}\text { Calculated } \\
\text { parameters }\end{array}$ & $\begin{array}{l}\text { B-Interval } \\
(3317-3506)\end{array}$ & $\begin{array}{c}\text { Zone-A (3318- } \\
\text { 3328) }\end{array}$ & $\begin{array}{c}\text { Zone-B } \\
(3352-3362)\end{array}$ \\
\hline $\begin{array}{l}\text { Average volumeof } \\
\text { shale (Vshavg) }\end{array}$ & $51 \%$ & $28 \%$ & $26 \%$ \\
\hline $\begin{array}{l}\text { Average Sonic log } \\
\text { porosity }\left(\varnothing_{\text {Savg }}\right)\end{array}$ & $10 \%$ & $10 \%$ & $8 \%$ \\
\hline $\begin{array}{c}\text { Total porosity(PHIT) } \\
\left.\text { ( } \varnothing_{\text {avg }}\right)\end{array}$ & $10.5 \%$ & $7 \%$ & $9 \%$ \\
\hline $\begin{array}{l}\text { AverageEffective } \\
\text { porosity }\left(\varnothing_{\text {eavg }}\right)\end{array}$ & $10 \%$ & $8 \%$ & $9 \%$ \\
\hline $\begin{array}{c}\text { AverageWater } \\
\text { saturation }\left(\mathrm{S}_{\mathrm{wavg}}\right)\end{array}$ & $40 \%$ & $32 \%$ & $34 \%$ \\
\hline $\begin{array}{l}\text { AverageHydrocarbon } \\
\text { saturation }\left(\text { Shavg }_{\text {have }}\right.\end{array}$ & $60 \%$ & $58 \%$ & $62 \%$ \\
\hline
\end{tabular}
respectively.

Table 4. Calculated parameters in zone A of Miano - 9

\begin{tabular}{|c|c|c|}
\hline Calculatedparameters & $\begin{array}{c}\text { B-Interval(3331- } \\
\mathbf{3 3 8 9})\end{array}$ & $\begin{array}{c}\text { Zone-A (3337- } \\
\mathbf{3 3 4 7})\end{array}$ \\
\hline $\begin{array}{c}\text { Average volume of shale } \\
(\text { Vsh }\end{array}$ & $44 \%$ & $24 \%$ \\
\hline $\begin{array}{c}\text { AverageSoniclog porosity }(\varnothing \\
\text { Savg) }\end{array}$ & $11.3 \%$ & $18 \%$ \\
\hline Total porosity (PHIT) ( $\left.\varnothing_{\text {avg }}\right)$ & $11.8 \%$ & $12 \%$ \\
\hline $\begin{array}{c}\text { Average Effective porosity ( } \\
\text { eavg) }\end{array}$ & $6.4 \%$ & $8 \%$ \\
\hline $\begin{array}{c}\text { Average Water saturation } \\
\text { (Swavg) }\end{array}$ & $51.7 \%$ & $38 \%$ \\
\hline $\begin{array}{c}\text { Average hydrocarbon saturation } \\
\text { (Shavg) }\end{array}$ & $47.2 \%$ & $62 \%$ \\
\hline
\end{tabular}

Table 5. Calculated Parameters in B- interval of Miano-10

\subsubsection{Rock physics}

Rock physics is the term that contains the techniques relating the geological properties of rocks with the corresponding elastic and seismic properties under certain physical conditions [19].

Rock Physics uses the porosity logs and also the shear velocity $\operatorname{logs}$.

The aim of the rock physics is to establish P-wave (Vp), Swave (Vs) velocities, density and their relationship with elastic moduli.

Rock Physics gives idea about velocities and elastic parameters.

By observing the rock behavior of $\mathrm{Vp}, \mathrm{Vs}$, ratio of $\mathrm{Vp}$ versus $\mathrm{Vs}$ and the poison ratio we can describe their behavior in the reservoir.

Rock Physics may use information provided by the Petrophysicist, such as shale volume, saturation levels, and porosity in establishing relations between rock properties or in performing fluid substitution analyses [19].

Seismic waves traveling through the earth create small, short term, strains in the rock that lie in the elastic regime of the rocks. Therefore, using the assumptions outlined below, we were able to calculate useful elastic moduli such as Young's modulus and Poisson's ratio [20] or the LMR (Lame's modulus, shear modulus, and density) parameters $[21,22]$. The moduli are described as dynamic because they are measured by relatively high frequency measurements of velocities of elastic waves [21]. These dynamic moduli measured by seismic and well $\operatorname{logs}$ occur in the high frequency range and with low strain amplitudes [23].

The work flow carried out in determining the rock physics properties is summarized in Figure 13.

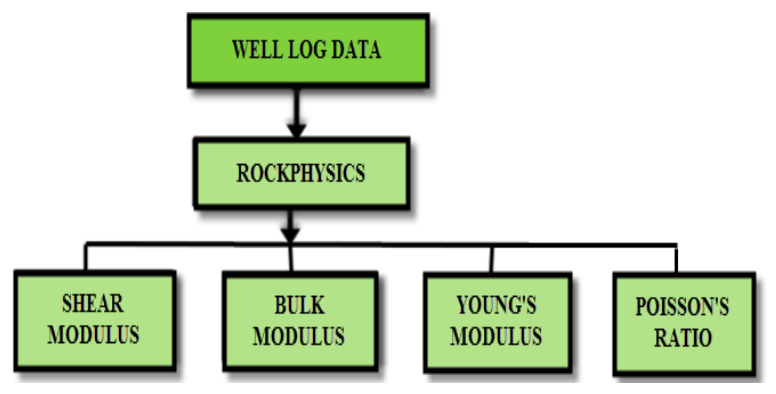

Figure 13. Work flow in determining rock properties 


\subsubsection{Stress}

The stress is the ratio of the force to the area on which the force is applied.

\subsubsection{Strain}

When an elastic body is subjected to stresses, changes in shape and dimensions occur. These changes, so called strains, can be resolved into certain fundamental types.

$$
\text { As } \sigma \propto \varepsilon \text { then } \sigma=C \mathcal{E}
$$

\subsubsection{Shear modulus}

Shear modulus is the ratio of shear stress to shear strain. It is related to the deformation of the solid when force is applied on it.

$$
\mu=\rho^{*} V s
$$

\subsubsection{Bulk modulus}

Bulk modulus is defined as it measures the resistance of the substance against compression.It is the ratio of volume stress to volume strain. It is calculated by using Equation

$$
K=\boldsymbol{\rho}\left(V p^{2}-4 / 3 V s^{2}\right)
$$

\subsubsection{Young modulus}

Young's modulus is the stress needed to compress the solid to shorten in a unit strain. It can be defined as "Ratio of uniaxial stress over uniaxial strain in the range of stress in which Hook's law is valid. It can be computed as;

$$
E=\sigma / \epsilon
$$

\subsubsection{Poisson ratio}

Poisson's ratio, sometimes denoted by the Greek letter small sigma (б), is to some extent neglected elastic constant. It is related to other elastic constants by a simple set of equations.

$$
\boldsymbol{\sigma}=0.5\left(\mathrm{Vp}^{2-}-2 \mathrm{Vs}^{2}\right) / \mathrm{Vp}^{2}-\mathrm{Vs}^{2}
$$

Plots of these properties of both wells are given below in Figure 14 (a) and (b) and each property in B-interval was determined.

\section{RESULT AND DISCUSSION}

After designing a base map falling at Universal Transverse Marcator (UTM), a Synthetic seismogram of Miano-9 was produced to confirm the B-Interval of Lower Goru Formation in the Lower Indus basin, Pakistan (Figure 6). The Synthetic seismogram of Miano-9 on the line P2094-223 was made.

The Synthetic seismogram was helpful in identifying the exact location of the formation tops, picked in time domain, then it was tied and has verified the top of B-interval. Moreover, all consigned lines were then further interpreted by making Fault polygon and contours. Five main faults (F1, F2, F3, F4 \& F5) along with three Horizon (Figure 5a) were identified mainly with the reflector stability and values from Time Depth (TD) chart (Figure 8 \& 9b).

The fault polygons (Figure 7) have represented the horst and grabens of B-interval (reservoir zone). The structural peaks and depressions are evident from the Color bar. It is noticeably made known through time contour map (Figure 8) that horst and graben structures are formed in the study area and the favorable site for hydrocarbon accumulation is horst. The color variation and color bar made it clear that small values of time displays horst while great values of time are graben.

It is also clearly obvious through contouring in maps (Figure 8 and 9b) that the study area is comparatively elevated area. Figure 7 shows fault polygon which confirms the horst and graben structure, latterly. Whereas, Figure 8 shows time contour map which also confirms low values of time at shallow regions named as graben while high values of time confirms host structure. In depth contouring map section the green color in Figure 9 (b) represents the shallowest horst having low values of profundity, which might be the good zone for the accretion of hydrocarbons because hydrocarbons move towards low pressure area. Similarly, wells can be seen in the maximum depth section which confirms the more precise estimations in interpretation.

Well log is a proficient tool in reservoir characterizations, hence employed in this research. Moreover, it is effective in understanding the subsurface geology and other physical conditions.

The Petrophysical interpretation of Zone A of B-interval in Miano-9 indicates shale volume of about $24 \%$, sonic porosity up to $18 \%$, total porosity up to $12 \%$, average effective porosity up to $8 \%$, water saturation up to $38 \%$ and average hydrocarbon saturation of about $62 \%$ in the well bore. However, the following parameters in B-interval of Miano10 includes the average volume of shale up to $51 \%$, sonic porosity up to $10 \%$, total porosity up to $10.5 \%$, average effective porosity up to $10 \%$, water saturation up to $40 \%$ and hydrocarbon saturation up to $60 \%$ in the well. Moreover, the well $\log$ studies from Figure 12 (a)and (b) indicate that the Lower Goru Formation is mainly composed of shale with interbedded sandstone.

Rock properties were calculated to confirm the marked zone and to check the behavior of these properties in this zone. The values of young's, shear, bulk modulus, Vp/Vs and Poisson's ratio as derived through the equations 16 to 19 are low in Miano 9 and 10. The behaviour of these rock properties can be understood through the Figure 14.

\section{CONCLUSIONS}

The seismic interpretations have shown the horst and Graben structure in the area and time depth contour maps have revealed that the horsts are the favorable structures for hydrocarbon accretion in Lower Goru B- interval zone. Moreover, the Petrophysical parameters indicating a higher hydrocarbon saturation in the rocks. Furthermore, the sandstone of the Formation is porous and permeable and hence can act as a good hydrocarbon reservoir. Similarly, the low values of young's, shear, bulk modulus, (velocity ratio $\mathrm{Vp} / \mathrm{Vs}$ ) and Poisson's ratios as determined through the rock physics have revealed the marked zone as hydrocarbon bearing zone. So, by integrating Seismic, Petrophysics and Rock physics studies in reservoir characterization, it is concluded that theB-interval of Lower Goru Formation may possess good Hydrocarbon reserves. However, in order to achieve more better results in characterization of reservoirs, the Geochemical studies are essential. 


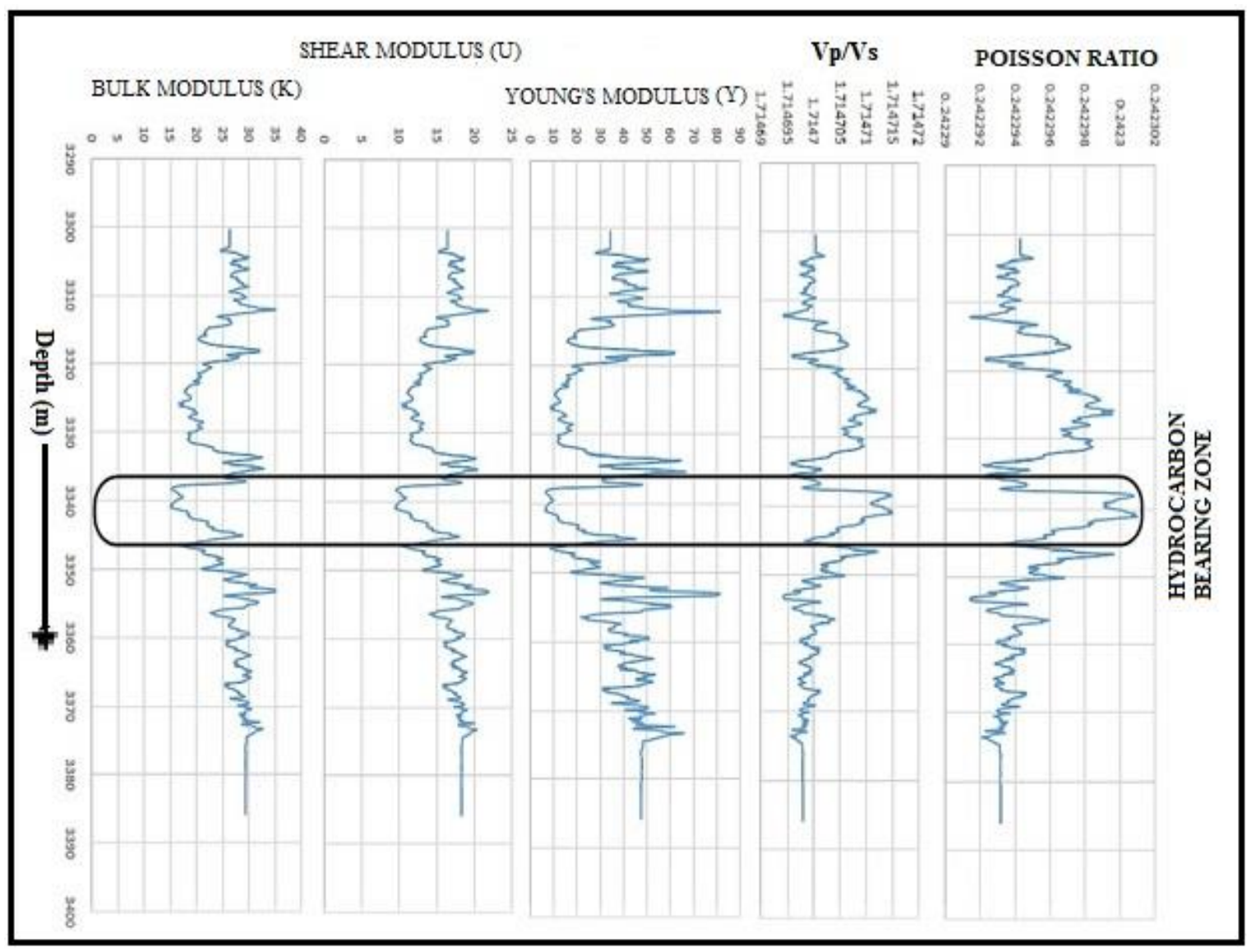

(a) Rock properties of Miano-9

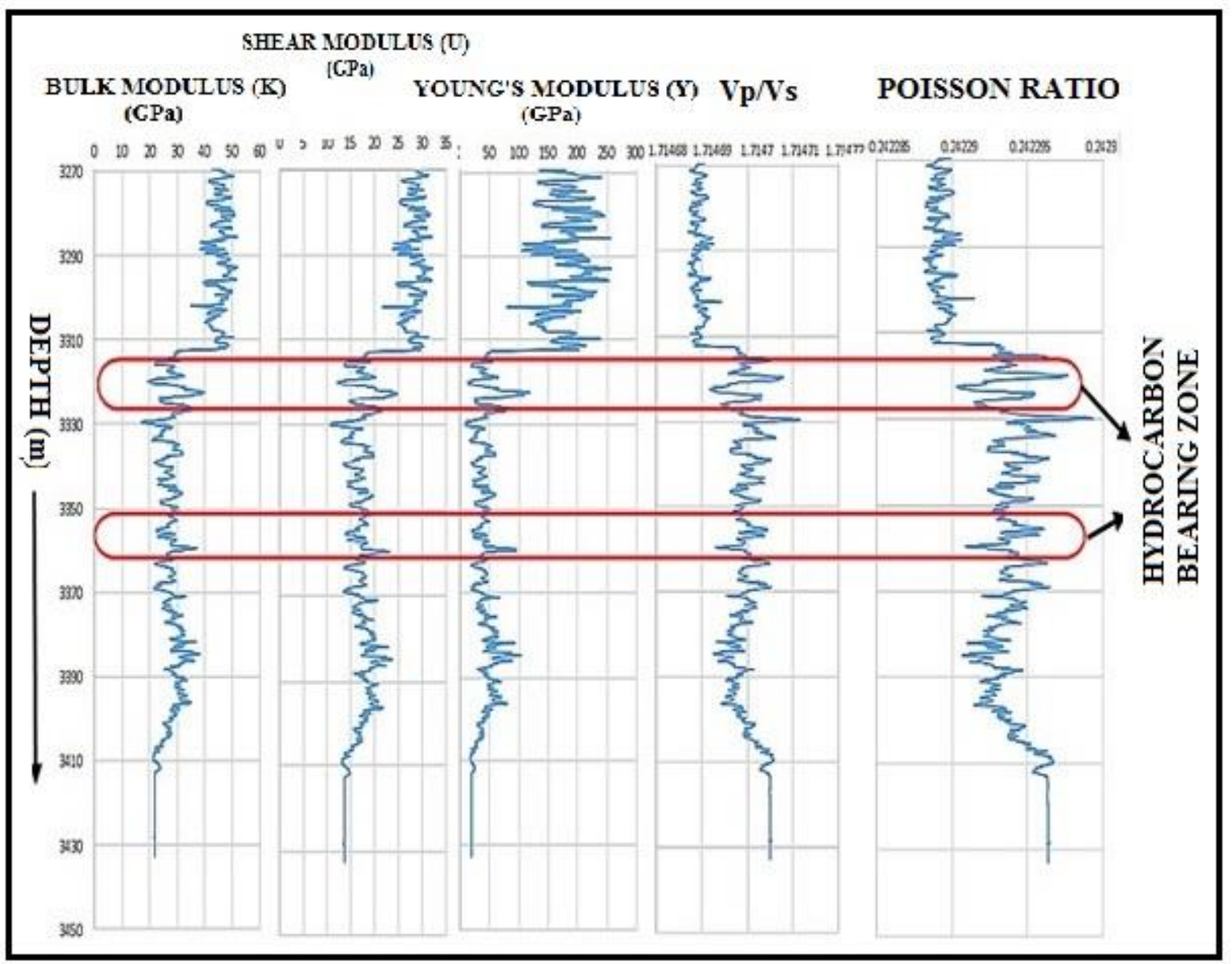

(b) Rock properties of Miano-10

Figure 14. Behaviour of rock properties calculated from Miano-9 and Miano-10 wells 


\section{ACKNOWLEDGMENT}

The authors are highly thankful to the Directorate General of Petroleum Concessions (DGPC), Pakistan, for the data being employed in this research work.

\section{REFERENCES}

[1] Dobrin, M.B., Savit, C.H. (1988). Introduction to Geophysical Prospecting. McGraw Hill Book Co., Inc., New York.

[2] El-Mowafy, H., Marfurt, K. (2008). Structural interpretation of the middle Frio formation using 3D seismic and well logs: An example from the Texas gulf coast of the United State. The Leading Edge, 27(7): 840-848. https://doi.org/10.1190/1.2954023

[3] Khalid, P., Broseta, D., Nichita, D.V., Blanco, J. (2014). A modified rock physics model for analysis of seismic signatures of low gas-saturated rocks. Arabian Journal of Geosciences, 7: 3281-3295. https://doi.org/10.1007/s12517-013-1024-0

[4] Evans, W.S. (1996). Technologies for multidisciplinary reservoir characterization. Journal of Petroleum Technology, 24-25.

[5] Stewart, M., Lonergan, L., Hampson, G. (2012). 3D seismic analysis of buried tunnel valleys in the Central North Sea: Tunnel valley fill sedimentary architecture. Geological Society, London, Special Publications, 368(1): 173-184. https://doi.org/10.1144/SP368.9

[6] Løseth, H., Gading, M., Wensaas, L. (2009). Hydrocarbon leakage interpreted on seismic data. Marine Petroleum Geology, 26(7): 1304-1319. https://doi.org/10.1016/j.marpetgeo.2008.09.008

[7] Avseth, P., Mukerji, T., Mavko, G. (2010). Quantitative Seismic Interpretation: Applying Rock Physics Tools to Reduce Interpretation Risk. Cambridge University Press

[8] Sahito, A.G., Solangi, S.H., Usmani, P., Brohi, I.A., Napar, L.D., Khokhar, Q. (2013). Sedimentologic studies of upper sands of Lower Goru Formation based on well cuttings and wireline logs from wells of X Field in the subsurface of Sindh Monocline, Southern Indus Basin, Pakistan. Sindh University Research JournalSURJ (Science Series), 45.

[9] Ahmad, N., Fink, P., Sturrock, S., Mahmood, T., Ibrahim, M. (2004). Sequence stratigraphy as predictive tool in Lower Goru fairway, Lower Middle Indus Platform, Pakistan. PAPG-SPE ATC, pp. 85-105.

[10] Raza, H.A., Ahmed, R., Sheikh, S.M. (1989). Exploration performance in sedimentary zone of Pakistan. Journal of Hydrocarbon Institute of Pakistan. Records, 1(1): 1-7.

[11] Kadri, I.B. (1995). Petroleum geology of Pakistan. Graphic Publishers, Karachi, 93-108.

[12] Wandrey, C.J., Law, B.E., Shah, H.A. (2004). Sembar Goru/Ghazij composite total petroleum system, Indus and Sulaiman-Kirthar Geologic Provinces, Pakistan and India. United States Geological Survey Bulletin, 2208-C.

[13] Krois P, Mahmood, T., Milan, G. (1998). Miano field, Pakistan a case history of model driven exporation. Proceedings of the Pakistan Petroleum Convention 98, Pakistan. Association of Petroleum Geologists Islamabad, pp. 111-131.
[14] Azeem, T., Yanchun, W., Khalid, P., Xueqing, L., Yuan, F., Lifang, C. (2016). An application of 508 seismic attributes analysis for mapping of gas bearing sand zones in the Sawan gas field Pakistan. Geodaetica et Geophysica, 51: 732-744. https://doi.org/10.1007/s40328-015-0155-z

[15] Kearey, P., Klepeis, K.A., Vine, F.J. (2009). Global tectonics. John Wiley \& Sons.

[16] Kafisanwo, O.O., Abe, J.S., Falade, A.O. (2019). Generating pseudo-synthetic seismogram with resistivity logs considering the effect of gas: Application to Bizzy field, onshore, Niger-delta, Nigeria. Environmental and Earth Sciences Research Journal, 6(4): 149-161. https://doi.org/10.18280/eesrj.060402

[17] Hilchie, D. (1978). Applied Openhole Log Interpretation. DwHilchie, Inc, Golden.

[18] Asquith, G.B., Krygowski, D., Gibson, C.R. (2004). Basic Well Log Analysis (Vol. 16). Tulsa: American Association of Petroleum Geologists.

[19] Dewar, J., Pickford, S. (2001). Rock physics for the rest of us-an informal discussion. CSEG Recorder, 26(5): 42-49.

[20] Rickman, R., Mullen, M., Petre, E., Grieser, B., Kundert, D. (2008). A practical use of shale petrophysics for stimulation design optimization: All shale plays are not clones of the Barnett Shale: SPE 115258. In Proc. Ann. Tech. Conf., Denver, Co., USA. https://doi.org/10.2118/115258-MS

[21] Goodway, B., Chen, T., Downton, J. (1997). Improved AVO fluid detection and lithology discrimination using Lamépetrophysical parameters; " $\lambda \rho "$ ", " $\mu \rho ", \&$ " $\lambda / \mu$ fluid stack", from $\mathrm{P}$ and $\mathrm{S}$ inversions. In SEG Technical Program Expanded Abstracts 1997, 183-186. https://doi.org/10.1190/1.1885795

[22] Gray, D. (2002). Elastic inversion for Lamé parameters. In SEG Technical Program Expanded Abstracts 2002, 213-216. https://doi.org/10.1190/1.1817128

[23] Prasad, M., Fabricius, I.L., Olsen, C. (2005). Rock physics and statistical well log analyses in marly chalk. The Leading Edge, 24(5): 491-495. https://doi.org/10.1190/1.1926806

\section{NOMENCLATURE}

$\begin{array}{ll}I & \text { Acoustic impedance } \\ R C & \text { Reflection coefficient } \\ v & \text { Velocity at well point } \\ t & \text { Travel time } \\ T W T & \text { Two way Travel Time } \\ V_{S h} & \text { Volume of shale } \\ G R_{\min } & \text { Minimum value of GR log } \\ G R_{\max } & \text { Maximum value of GR log } \\ \Phi S & \text { Sonic porosity } \\ \Delta \mathrm{t} & \text { travel transit time } \\ \Delta T_{\text {mat }} & \text { Transit time in matrix } \\ \Delta T_{f} & \text { Transit time in fluids } \\ \mu S / f t & \text { Microseconds per feet } \\ \Phi T & \text { Total Porosity } \\ \Phi n & \text { Neutron porosity } \\ \Phi S & \text { Sonic Porosity } \\ \Phi e & \text { effective porosity } \\ S_{w} & \text { Water saturation } \\ R_{w} & \text { Resistivity of water }\end{array}$


$R_{t}$

F

$n$

$a$

$m$

$S_{h c}$

$S_{w}$

Vs

$V p$
True Formation Resistivity

Formation factor

saturation exponent usually taken as 2 but the value varies between $1.8-2.5$

Constant and equal to 1 for sandstone

Cementation factor and 2 for sandstone

Hydrocarbon saturation

Water saturation

S-wave velocity

p-wave velocity

\section{Greek symbols}

$\Delta \quad$ Variations of variables

$\boldsymbol{\rho} \quad$ Density

$\sigma \quad$ stress

$\varepsilon \quad$ Strain

$C \quad$ stiffness constant

$\phi \quad$ Porosity

$\mu \quad$ Shear modulus

$K \quad$ Bulk modulus

$E \quad$ Young modulus

$\boldsymbol{\sigma} \quad$ Poisson ratio 